\section{Self-care practice and associated factors among type 2 adult diabetic patients on follow up clinic of Dessie referral hospital, Northeast Ethiopia}

\author{
Sisay Gedamu Addis ${ }^{1 *}$, Sewunet Ademe Kassahun", Samuel \\ Anteneh Ayele $^{2}$, Abebe Dires Nega ${ }^{1}$ and Kirubel Dagnaw \\ Tegegne $^{1}$
}

${ }^{1}$ Department of Comprehensive Nursing, School of Nursing and Midwifery, College of Medicine and Health Sciences, Wollo University, P.O.BOX:1145, Dessie, Ethiopia

2Department of Adult Health Nursing, School of Nursing and Midwifery, College of Medicine and Health Sciences, Wollo University, P.O.BOX:1145, Dessie, Ethiopia

\section{Abstract}

Background: Diabetes mellitus is a common health problem in the world and Africa including Ethiopia. Its complication is the major cause of morbidity and mortality of people due to improper self-care practice.

Objective: To assess self-care practices and associated factors among type 2 adult diabetic patients on follow-up clinic of Dessie referral hospital, Ethiopia.

Method: Institutional based cross sectional study was conducted. Total of 278 type 2 diabetic patients was selected by systematic random sampling technique and data was collected by interviewer administered pretested questionnaire. Epidata 3.1 and SPSS version 23 software were used for data entry and analysis, respectively. In bivariate analysis, variables having a $p$ - value of $<0.2$ were entered to multivariate analysis model and statistical significance was declared at $p$ - value of $<0.05$ and $95 \%$ confidence interval.

Results: The response rate was $269(96.76 \%)$ of the total 278 participants. Among the respondents $150(55.8 \%)$ had good diabetic self-care practice. This study showed that primary school education level $(A O R=2.592,95 \% \mathrm{Cl}=1.104-6.087, p=0.029)$, secondary school education level $(A O R=3.873,95 \% \mathrm{Cl}=1.325-11.323, p=0.013)$, college/university graduate $(A O R=3.030$, $95 \% \mathrm{Cl}=1.276-7.197,0.012)$, attended diabetic education regularly $(\mathrm{AOR}=2.981,95 \% \mathrm{Cl}=1.050$ $8.462, p=0.040$ ), member of diabetic association (AOR=3.496, $95 \% \mathrm{Cl}=1.440-8.483, p=0.006$ ) and having glucometer at home $(\mathrm{AOR}=2.634,95 \% \mathrm{Cl}=1.357-5.111, p=0.004)$ were significantly associated with diabetes self-care practice.

Conclusion: Nearly half of diabetic patients had poor self care practice. Hence, there is a need to improve diabetic self-care practice. Attention should be given by policy makers, Dessie referral hospital, health care professionals, diabetic associations and researchers.
More Information

*Address for Correspondence: Sisay Gedamu Addis, Department of Comprehensive Nursing, School of Nursing and Midwifery, College of Medicine and Health Sciences, Wollo University, P.O.BOX:1145, Dessie, Ethiopia, Tel: +251920553732; +251935574801; Email: sgsisay4@gmail.com

Submitted: April 24, 2021

Approved: June 04, 2021

Published: June 07, 2021

How to cite this article: Addis SG, Kassahun SA, Ayele SA, Nega AD, Tegegne KD. Self-care practice and associated factors among type 2 adult diabetic patients on follow up clinic of Dessie referral hospital, Northeast Ethiopia. Clin J Nurs Care Pract. 2021; 5: 031-037.

DOI: 10.29328/journal.cjncp.1001034

ORCiD: orcid.org/0000-0001-6486-9125

Copyright: @ 2021 Addis SG, et al. This is an open access article distributed under the Creative Commons Attribution License, which permits unrestricted use, distribution, and reproduction in any medium, provided the original work is properly cited.

Keywords: Self-care practice; Associated factors; Type 2 diabetic patients; Adult; Dessie referral hospital; Northeast Ethiopia

Abbreviations: AOR: Adjusted Add Ratio; BP Blood Pressure; $\mathrm{Cl}$ : Confidence Interval; COR: Crude Odd Ratio; DM: Diabetes Mellitus; ETB: Ethiopian Birr; SD: Standard Deviation; SPSS: Statistical Program for Social Sciences

Check for updates

OPEN ACCESS

\section{Introduction}

Diabetes mellitus (DM) is the disturbance of metabolism characterized by chronic hyperglycemia and the cause can be impaired insulin secretion, action or both secretion and action problems [1]. Type 2 diabetes is described as the combination of peripheral insulin resistance and inadequate insulin secretion by pancreatic beta cells. The resistance of insuline resulted in elevation of free fatty acids and inflammatory cytokines that leads to impaired glucose transportation in muscle cells, raised gluconeogenesis by the liver and fat breakdown [2]. Type 2 diabetes due to a progressive loss of b-cell insulin secretion frequently on the background of insulin resistance [3]. Self-care practice in diabetes patient is critical to keep the disease under control and about $95 \%$ of the diseases management is usually carried 
out by the affected individual or their families. These practices includes blood glucose monitoring, dietary modification, physical activity, and compliance to medications [4-6]. Selfmanagement requires active involvement of the individual in their care that needs high commitment and the self care behaviors affects its out come. Evidence showed that, diabetes patients who were regularly participated in self care practices have succeeded better blood glucose control. Patients with diabetes mellitus had been shown to make a dramatic change on the progression and development of their disease by participating in their own self care [7-10].

Although diabetic patients visit clinics regularly, their blood glucose level remains high [11]. Worldwidely, the prevalence of diabetes patients among adults (aged 20-79 years) was 6.4\%, affecting 285 million in 2010, and in 2030 it will increase to $7.7 \%$ by affecting 439 million adults. Between 2010 and 2030, there will be a $69 \%$ increase in numbers of diabetes adult patients in developing countries and a $20 \%$ increase in developed countries [12].

Properly uncontrolled type 2 diabetes end up with micro vascular, macro vascular and neuropathic complications. Diabetic micro vascular complications include retinal, renal and possibly neuropathic disease. Peripheral vascular and coronary artery diseases are macro vascular complications [13]. Diabetic complications lead to high morbidity and mortality and have great impact on patients productivity and quality of life. These complications include target organ damage, leg amputation, loss of vision and nerve injury. In addition diabetes and its complications come with extensive economic loss to diabetic people and their family, health care systems and to the national economies through medical costs and loss of work [14,15]. Adequate glycemic control and prevention of diabetic mellitus complications are the beginning point of treatment in diabetic patients. Screening and prevention of risk factors for type 2 diabetes patients are crucial and important to preserve a good quality of life in diabetic patients [16].

The progression of diabetes and its complications are mainly influenced by lack of awareness and poor self care practices. Regular practice had good outcomes for people with diabetes $[17,18]$. Diabetic self-care practices were recognized to be important and effective in diabetes control and to prevent complications. In Ethiopia previous finding revealed that, prescribed medication adherence practice was accomplished as recommended in majority respondents (93.2\%) but the problems were for other self care practices [19]. A study in Addis Ababa, Ethiopia showed that, 75.9\% of diabetes patients did not adhere to recommended diet management, $83.5 \%$ did not adhere to self-monitoring of blood glucose level but only $4.3 \%$ of the respondents did not adhere to the prescribed medications [20]. Another study done in public hospitals of Benishangul Gumuz regional state, Western part of Ethiopia showed that the overall poor self care practice was $45.7 \%$ from the total participants [21]. But the desirable self care behaviors among diabetes patients in Northwest Ethiopia was only 28.4\% [22]. In contrast another study done in Gondar referral hospital, Northwest Ethiopa $51.86 \%$ of diabetes mellitus patients had poor self care practice [23]. In Ethiopia, self care practice finding results were varied across different studies among type 2 diabetes mellitus patients. Furthermore, in Northeast Ethiopia selfcare practice of type 2 diabetic patients is not well studied. That is why this study was tried to assess self-care practices and associated factors of type 2 diabetes patients attending follow up units of Dessie referral hospital, Northeast Ethiopia.

\section{Materials and methods}

\section{Study design, area and period}

Cross sectional quantitative study done in Dessie referral hospital, from May 1 - 30, 2018. As it is the only referal hospital in Eastern Amhara it serves for South wollo zone, North wollo zone, Oromia special zone and some part of Afar region.

\section{Subjects}

This study was done on type 2 adult diabetic patients in Dessie referal hospital follow up clinic. A patient who diagnosed type 2 diabetes and made follow up for at least three months were included but critical ill and hearing impairment patients were excluded in the study.

\section{Sample size determination}

A single population proportion formula $[n=(Z$ $\left.a / 2)^{2} P(1-P) / d^{2}\right]$ was used to calculate the sample size. The sample size calculated by assuming self-care practice prevalence to be $56 \%$ in previous study in Tikur Anbessa specialized hospital with 5\% marginal error, $95 \%$ confidence interval [24]. Based on this assumption, the sample size for the study was 379 . Since the study population is less than 10,000 , we used population correction formulas to get 253 . Then 278 type 2 adult diabetic patients were the final sample size after adding $10 \%$ for non response rate.

\section{Sampling technique and procedure}

A systematic sampling technique was carried out to select patients where K calculated by total population ( $\mathrm{N}$ ) divided by total sample size $(n)$. Using the $K$ value the patient selected using patient registration number as a sampling frame and the first study subjects was selected by simple random sampling method.

\section{Data collection tools and procedure}

Data was collected by interview including socio demographic characterstics, health profile of participants, health belief questions and self-care practice related questions. Questions were adapted and modified contextually and proven to be reliable in similar studies [25-28]. The 
English version questionnaire translated in to local language (Amharic) by individuals who have good ability of the two languages then again to English by different person to ensure consistency. Training for data collectors and supervisor were given regarding the study, the questionnaire and data collection procedure by the main investigators. Week prior to the actual data collection, the questionnaire was pre-tested on $10 \%$ patients identified from Borumeda hospital which was not included in the actual data collection. Findings of the pretest incorporated to clarify the tool before the actual data collection.

\section{Operational definitions}

- Good practice: Overall practice was categorized as good if the total score was $\geq 60 \%$ of practice questions.

$>$ Poor practice: Overall practice was categorized as poor if the total score was $<60 \%$ of practice questions [20].

Adequate glycemic level: Fasting blood sugar measurement $\leq 125 \mathrm{mg} / \mathrm{dl}$.

Inadequate glycemic level: Fasting blood sugar level me asurement $\geq 126 \mathrm{mg} / \mathrm{dl}[29,30]$.

\section{Statistical analysis}

Descriptive statics was done to describe frequency and percentages. To see the crude significant association of each independent and dependent variables binary logistic regression analysis was performed. Independent variables found to be $p$ - value $<0.2$ entered to multivariate analysis to control the confounding. Finally statistical association determined by $p$ - value less than 0.05 and AOR at $95 \%$ confidence interval.

\section{Ethical consideration}

Ethical clearance was obtained from Wollo University College of medicine and health science research review committee. Written consent was obtained from all study participants after information is provided about the purpose of the study, non- invasiveness of the data collection procedure and confidentiality of the information.

\section{Results}

\section{Socio-demographic characteristics of the study participants}

Out of the total sample size ( $n=278), 269$ type 2 adult DM patients had completed the interview questionnaires making a response rate of $96.76 \%$ and the mean age of respondents was 52.52 years \pm 13.246 SD (ranged from 21 to 99). The study showed that $74(27.5 \%)$ of the participants found in the age category of 40-49 age group. Among 269 type 2 diabetic patients who completed the interview questionnaires, $150(55.8 \%)$ were males and $119(44.2 \%)$ of them were females (Table 1).

\section{Health profile of the participants}

Most of the respondents 161(59.9\%) had duration of diabetic disease less than 5 years. With regard to comorbidities, $88(32.7 \%)$ of them had other diseases in addition to diabetes mellitus. Sixty seven (24.9\%) of type 2 diabetes patients had family history of diabetes mellitus. The majority, 192(71.4\%) of respondents did not have glucometer at home (Table 2). From all participants, 235(87.4\%) of them had inadequate glycemic level when it was measured during data collection period in the morning (fast blood sugar level) (Figure 1).

\section{Diabetic self-care practice}

About 172(63.9\%) participants practiced regular blood

Table 1: Socio demographic characteristics of study participants on diabetes follow-up clinic at Dessie referral hospital, Ethiopia.

\begin{tabular}{|c|c|c|c|}
\hline Variables & Responses & $\begin{array}{c}\text { Frequency } \\
(n=269)\end{array}$ & Percentage(100) \\
\hline \multirow{5}{*}{ Age } & $<40$ & 48 & 17.8 \\
\hline & $40-49$ & 74 & 27.5 \\
\hline & $50-59$ & 54 & 20.1 \\
\hline & $60-69$ & 58 & 21.6 \\
\hline & $\geq 70$ & 35 & 13.0 \\
\hline \multirow{2}{*}{ Sex } & Male & 150 & 55.8 \\
\hline & Female & 119 & 44.2 \\
\hline \multirow{4}{*}{ Marital status } & Married & 202 & 75.1 \\
\hline & Single & 19 & 7.1 \\
\hline & Widowed & 31 & 11.5 \\
\hline & Divorced & 17 & 6.3 \\
\hline \multirow{6}{*}{ Educational level } & No formal education & 73 & 27.1 \\
\hline & Can read and write & 70 & 26.0 \\
\hline & Primary school & 41 & 15.2 \\
\hline & Secondary school & 22 & 8.2 \\
\hline & College/university & 21 & 7.8 \\
\hline & $\begin{array}{l}\text { College/university } \\
\text { graduate }\end{array}$ & 42 & 15.6 \\
\hline \multirow{6}{*}{ Occupation } & Student & 10 & 3.7 \\
\hline & Self employed & 110 & 40.9 \\
\hline & $\begin{array}{l}\text { Government } \\
\text { employed }\end{array}$ & 47 & 17.5 \\
\hline & Unemployed & 28 & 10.4 \\
\hline & House wife & 57 & 21.2 \\
\hline & Retired & 17 & 6.3 \\
\hline \multirow{4}{*}{$\begin{array}{l}\text { Monthly income } \\
\text { (ETB) }\end{array}$} & $\leq 999$ & 127 & 47.2 \\
\hline & $1000-1999$ & 50 & 18.6 \\
\hline & $2000-2999$ & 41 & 15.2 \\
\hline & $\geq 3000$ & 51 & 19.0 \\
\hline
\end{tabular}

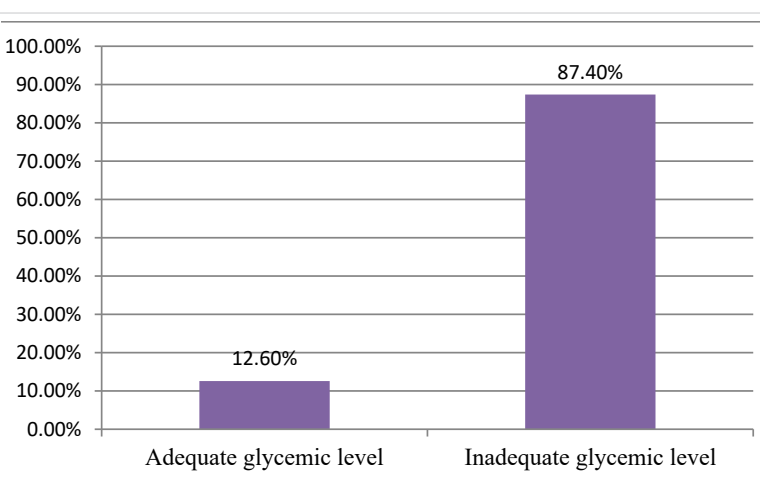

Figure 1: Adequacy of current fast blood sugar level of type 2 diabetic patients on diabetes follow-up clinic at Dessie referral hospital, Ethiopia. 
pressure monitoring at least every month, 258(95.9\%) visit their physicians at least every three months, 53(19.7\%) regular blood glucose testing at least once per week, $180(66.9 \%)$ managed their diet regularly, 101(37.5\%) had a regular exercise, $139(51.7 \%)$ yearly eye examination, $134(49.8 \%)$ check feet daily and $230(85.5 \%)$ of respondents had never forgotten their medication in the past 7 days (Figure 2). Overall 150(55.8\%) had good diabetic selfcare practice while $119(44.2 \%)$ had poor self-care practice (Figure 3).

\section{Factors associated with diabetes self-care practice}

Variables with p-value less than 0.2 in bivariate analysis were entered to multivariate analysis. Among these variables which were entered to multivariate analysis educational level, attended a diabetic education, member of diabetic association and having glucometer at home were found to be significantly statistical associated with diabetes self-care practice.

Diabetes self-carewas better practicedamongrespondents who attained primary school education (AOR $=2.592$, $95 \% \mathrm{CI}=1.104-6.087, p=0.029$ ), secondary school education (AOR=3.873, 95\%CI=1.325-11.323, $p=0.013$ ) and college/ university graduate (AOR=3.030, 95\%CI=1.276-7.197, 0.012 ) as compared to those who were no formal education. Respondents who follow diabetic education regularly were 3 times more likely practiced good diabetic self-care (AOR=2.981, 95\% $\mathrm{CI}=1.050-8.462$ ), $p=0.040$ ) as compared to those who were never follow diabetic education. Diabetic association membership (AOR=3.496, 95\% CI=1.440-8.483, $p=0.006)$ and having glucometer at home $(\mathrm{AOR}=2.634$, $95 \% \mathrm{CI}=1.357-5.111, p=0.004$ ) were more likely practiced diabetic self-care than their counterparts (Table 3).

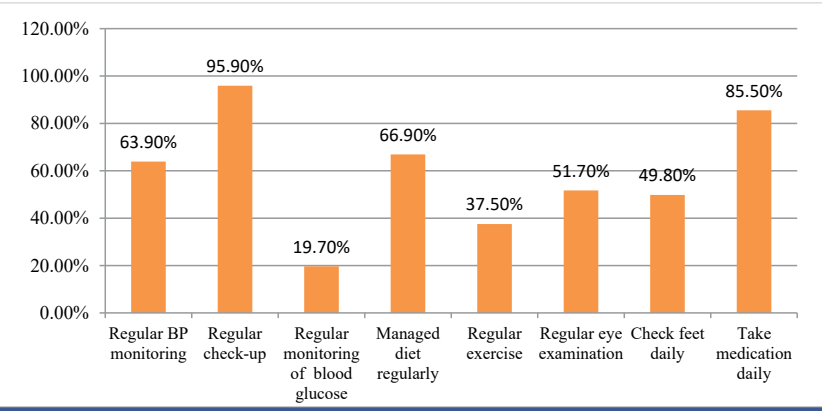

Figure 2: Diabetic self-care practice indicators of type 2 diabetic patients on diabetes follow-up clinic at Dessie referral hospital, Ethiopia.

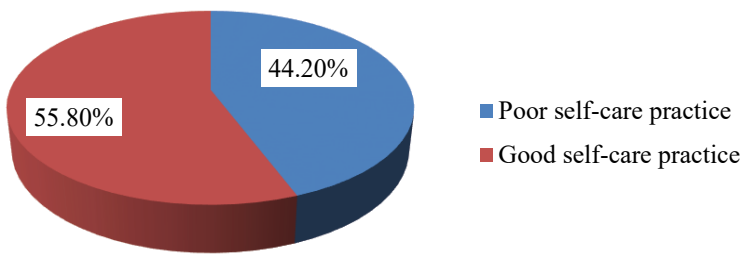

Figure 3: Overall diabetic self care of type 2 diabetic patients on diabetes followup clinic at Dessie referral hospital, Dessie town, Ethiopia.
Table 2: Health Profile of type 2 diabetic patients on diabetes follow-up clinic at Dessie referral hospital, Ethiopia.

\begin{tabular}{|c|c|c|c|}
\hline Variable & Responses & $\begin{array}{l}\text { Frequency } \\
(n=269)\end{array}$ & $\begin{array}{c}\text { Percentage } \\
(100 \%)\end{array}$ \\
\hline \multirow{3}{*}{$\begin{array}{c}\text { Duration of DM since } \\
\text { diagnosis }\end{array}$} & $<5$ years & 161 & 59.9 \\
\hline & $5-10$ years & 88 & 32.7 \\
\hline & $>10$ years & 20 & 7.4 \\
\hline \multirow{3}{*}{$\begin{array}{l}\text { Presence co- } \\
\text { morbidities }\end{array}$} & Yes & 88 & 32.7 \\
\hline & No & 151 & 56.1 \\
\hline & Don't know & 30 & 11.2 \\
\hline \multirow{4}{*}{ Current treatment } & Insulin injection & 68 & 25.3 \\
\hline & Oral medication & 158 & 58.7 \\
\hline & $\begin{array}{l}\text { Both insulin injection and } \\
\text { oral medication }\end{array}$ & 29 & 10.8 \\
\hline & I don't take medication & 14 & 5.2 \\
\hline \multirow{3}{*}{$\begin{array}{c}\text { Family history of } \\
\text { diabetes }\end{array}$} & Yes & 67 & 24.9 \\
\hline & No & 171 & 63.6 \\
\hline & Don't know & 31 & 11.5 \\
\hline \multirow{3}{*}{$\begin{array}{c}\text { Attended a diabetic } \\
\text { education }\end{array}$} & No never & 120 & 44.6 \\
\hline & Yes sometimes & 113 & 42.0 \\
\hline & yes regularly & 36 & 13.4 \\
\hline \multirow{2}{*}{$\begin{array}{l}\text { Member of diabetic } \\
\text { association }\end{array}$} & Yes & 51 & 19.0 \\
\hline & No & 218 & 81.0 \\
\hline \multirow{2}{*}{$\begin{array}{l}\text { Having glucometer } \\
\text { at home }\end{array}$} & Yes & 77 & 28.6 \\
\hline & No & 192 & 71.4 \\
\hline
\end{tabular}

\section{Discussion}

Overall, in this study $55.8 \%$ of the respondent had good and $44.2 \%$ poor diabetic self-care practice. This showed that presence of problem in diabetic patients concerning to diabetic self-care practice that needs immediate attention by the concerned bodies. The finding of this study overall diabetes self care practice in line with study conducted in Wester part of Ethiopia where $45.7 \%$ of respondents' had poor self care practice [21]. From different study findings, the diabetes self-care practice is not consistent. The overall good self-care practice of participants in this study (55.8\%) lower than the study done in Dilla university hospital (76.8\%) but higher than the study conducted in Harari town, Eastern Ethiopia (39.2\%), public hospitals of Tigray region centeral zone (37.3\%) and Bahir Dar, Northwest Ethiopia $[19,22,31,32]$. The variation might be due to the presence of difference in health care accessibility within the country and short consultation time during first diagnosis and follow up might discourage patients from attending their followups and accessing the required information regarding self-care practices. Although adequate diabetes self-care practice can be achieved through patient centered education, health professionals might fail to devote adequate time for discussion to educate and motivate patients to follow the recommended diabetes self-care practice due to high number of patients in the facilities. However this study was consistent to the study carried out in Nekemte referral hospital (55\%) [33]. The reason might be due to similarity of study design in this study and Nekemte referral hospital study.

Among the participants $95.9 \%$ of them had regular checkup. It is higher than a study done in India; only $58 \%$ had regular follow up [34]. This difference might be due to in our 


\begin{tabular}{|c|c|c|c|c|c|c|}
\hline \multirow[b]{2}{*}{ Variables } & \multirow[b]{2}{*}{ Response } & \multicolumn{2}{|c|}{ Self-care practice } & \multirow[b]{2}{*}{ COR(95\% C.I) } & \multirow[b]{2}{*}{ AOR(95\% C.I) } & \multirow[b]{2}{*}{$p$ - value } \\
\hline & & $\begin{array}{l}\text { Good } \\
\text { N (\%) }\end{array}$ & $\begin{array}{l}\text { Poor } \\
\text { N (\%) }\end{array}$ & & & \\
\hline \multirow{5}{*}{ Age } & $<40$ & $29(60.4)$ & $19(39.6)$ & 1 & 1 & \\
\hline & $40-49$ & $45(60.8)$ & $29(39.2)$ & $1.017(0.483-2.138)$ & $1.096(0.475-2.528)$ & 0.831 \\
\hline & $50-59$ & $34(63.0)$ & $20(37.0)$ & $1.114(0.501-2.478)$ & $1.564(0.622-3.930)$ & 0.342 \\
\hline & $60-69$ & $26(44.8)$ & $32(55.2)$ & $0.532(0.245-1.157)$ & $0.647(0.264-1.586)$ & 0.341 \\
\hline & $\geq 70$ & $16(45.7)$ & $19(54.3)$ & $0.552(0.229-1.332)$ & $0.902(0.313-2.603)$ & 0.849 \\
\hline \multirow{6}{*}{ Educational level } & No formal education & $27(37.0)$ & $46(63.0)$ & 1 & 1 & \\
\hline & Can read and write & $41(58.6)$ & $29(41.4)$ & $2.409(1.230-4.718)$ & $1.781(0.856-3.703)$ & 0.122 \\
\hline & Primary school & $25(61.0)$ & $16(39.0)$ & $2.662(1.212-5.849)$ & $2.592(1.104-6.087)$ & $0.029^{*}$ \\
\hline & Secondary school & $15(68.2)$ & $7(31.8)$ & $3.651(1.323-10.076)$ & $3.873(1.325-11.323)$ & $0.013^{*}$ \\
\hline & College/ university & 13(61.9) & $8(38.1)$ & $2.769(1.018-7.531)$ & $2.596(0.882-7.640)$ & 0.083 \\
\hline & College/ university graduate & $29(69.0)$ & $13(31.0)$ & $3.801(1.693-8.531)$ & $3.030(1.276-7.197)$ & $0.012^{*}$ \\
\hline \multirow{6}{*}{ Occupation } & Student & $5(50.0)$ & $5(50.0)$ & 1 & 1 & \\
\hline & Self employed & $58(52.7)$ & $52(47.3)$ & $1.115(0.306-4.072)$ & $1.538(0.286-8.282)$ & 0.616 \\
\hline & Employed & $34(72.3)$ & $13(27.7)$ & $2.615(0.648-10.549)$ & $2.138(0.407-11.213)$ & 0.369 \\
\hline & Unemployed & $13(46.4)$ & $15(53.6)$ & $0.867(0.204-3.676)$ & $2.033(0.305-13.552)$ & 0.464 \\
\hline & House wife & $28(49.1)$ & $29(50.9)$ & $0.966(0.252-3.702)$ & $1.381(0.230-8.291)$ & 0.724 \\
\hline & Retired & $12(70.6)$ & $5(29.4)$ & $2.400(0.475-12.130)$ & $2.692(0.352-20.571)$ & 0.340 \\
\hline \multirow{4}{*}{ Current treatment } & Insulin injection & $42(61.8)$ & $26(38.2)$ & 1 & 1 & \\
\hline & Oral medication & $83(52.5)$ & $75(47.5)$ & $0.685(0.383-1.224)$ & $1.054(0.532-2.085)$ & 0.881 \\
\hline & $\begin{array}{l}\text { Both insulin injection and oral } \\
\text { medication }\end{array}$ & 19(65.5) & $10(34.5)$ & $1.176(0.474-2.918)$ & $1.450(0.490-4.295)$ & 0.502 \\
\hline & I don't take medication & $6(42.9)$ & $8(57.1)$ & $0.464(0.145-1.490)$ & $0.484(0.113-2.068)$ & 0.327 \\
\hline \multirow{3}{*}{ Family history of diabetes } & Yes & $45(67.2)$ & $22(32.8)$ & 1 & 1 & \\
\hline & No & $93(54.4)$ & $78(45.6)$ & $0.583(0.322-1.054)$ & $0.864(0.439-1.699)$ & 0.671 \\
\hline & Don't know & $12(38.7)$ & $19(61.3)$ & $0.309(0.128-0.748)$ & $0.476(0.172-1.312)$ & 0.151 \\
\hline \multirow{3}{*}{$\begin{array}{l}\text { Attended a diabetic } \\
\text { education }\end{array}$} & No, never & $54(45.0)$ & $66(55.0)$ & 1 & 1 & \\
\hline & Yes, sometimes & $66(58.4)$ & $47(41.6)$ & $1.716(1.021-2.884)$ & $1.692(0.962-2.975)$ & 0.068 \\
\hline & Yes, regularly & $30(83.3)$ & $6(16.7)$ & $6.111(2.369-15.761)$ & $2.981(1.050-8.462)$ & $0.040^{*}$ \\
\hline \multirow{2}{*}{$\begin{array}{l}\text { Member of diabetic } \\
\text { association }\end{array}$} & Yes & $43(84.3)$ & $8(15.7)$ & $5.576(2.505-12.410)$ & $3.496(1.440-8.483)$ & $0.006^{*}$ \\
\hline & No & 107(49.1) & $111(50.9)$ & 1 & 1 & \\
\hline \multirow{2}{*}{ Having glucometer at home } & Yes & $60(77.9)$ & $17(22.1)$ & $4.000(2.177-7.351)$ & $2.634(1.357-5.111)$ & $0.004^{*}$ \\
\hline & No & $90(46.9)$ & 102(53.1) & 1 & 1 & \\
\hline \multirow{2}{*}{ Perceived Susceptibility } & Low & $61(50.4)$ & $60(49.6)$ & 1 & 1 & \\
\hline & High & $89(60.1)$ & $59(39.9)$ & $1.484(0.913-2.410)$ & $1.420(0.819-2.459)$ & 0.211 \\
\hline
\end{tabular}

study DM patients may respect the health professionals what they told with regard to regular check-up. The big problems in our study was even if the patient come to the hospital regularly they may not get appropriate checkup due to the hospital set up problems like absence of equipment used for check up and short consultation time by health professionals.

Here in our study regular monitoring of blood glucose which was the least $(19.7 \%)$ practiced self-care among overall self care was lower than the study conducted on type 2 DM patients in China (56.0\%) [35]. The possible difference might be due to less likely awareness about blood glucose monitoring in the current study. To support this in the present study current fast blood sugure $87.4 \%$ of the participant were inadequate glycemic level. China as she is developed country so that the people of china may have more awareness about regular blood glucose monitoring when we compare with the current study area. But in this study regular monitoring of blood glucose similar with study done in Dilla referral hospital (20\%) [19].

Managed diet regularly was $66.9 \%$ which is lower than the study in China (85.4\%) [35]. But higher than a study in Dilla specialized hospital Ethiopia (49.7\%) and Malaysia $(16.4 \%)[19,36]$. This variation may be due to the difference in setting, sociocultural variation, life style difference and finance barrier with poor perception toward the importance diet plan across the different studies.

In the current study regular exercise was $37.5 \%$ which is lower than a study conducted in Dilla referral hospital (44.5\%), India (45\%) and China (77.3\%) [19,34,35]. This might be due to the health care professionals did not give enough time to explain about exercise during first diagnosed and follow up as expected.

Check feet daily (49.8\%) which is higher than a research carried out in India (4\%) [34]. This variation might be due to failure of the health professional to explain the importance of foot care in India.

Take medication daily (85.5\%) which was lower than a study done in Dilla referral hospital (93.2\%) and higher than a research carried out in India (58.4\%) [19,34]. The discrepancy may be due to presence of variation access 
for diabetic information about anti-diabetic medications and unequal distribution of diabetic educators across the different studies.

The findings of this study showed that educational level, attended a diabetic education, member of diabetic association and having glucometer at home were found to be significantly statistical associated with diabetes selfcare practice in multivariate regression model analysis. Diabetes self-care was better practiced among respondents who attained primary school education, secondary school education and college/university graduate as compared to no formal education. The same findings had been recorded in other studies $[24,31,33]$. This might be due to the fact that those who have formal education might have gained more information how to perform diabetic self-care activities.

Attended a diabetic education and being diabetic association membership were significantly associated with diabetic self-care practice. Participants, who attend diabetic education regularly 3 times more likely to have good selfcare practice than those who were never follow diabetic education.This might be due to diabetic association regular monthly diabetic education and support given to patients such as securing medicine to some of the lower income members and relatively lower price for blood glucose testing. The study also revealed having glucometer at home was associated with good self-care practice which is similar to the study done in Tikur Ambesa referral hospital [24]. In contrast, in Benishangul Gumuz regional state public hospitals those diabetes patients who had no glucometer had significantly associated with poor self care practice [21]. A possible explanation for this could be having glucometer at home might reinforce patients to control their blood glucose level regularly but having no glucometer might affect diabetic patients negatively to control their blood glucose level.

\section{Limitations of the study}

Since cross sectional study design used the direction of relationship between variables can't always be determined. The result of self care activities may be affected by recall bias as it was obtained by self-reports. The findings in this study were based on quantitative method only that lacked triangulation with other methods like focus group discussion and in-depth interview.

\section{Conclusion}

This study reflects that diabetes self-care practice among patients was not adequate. Some critical practice gaps were identified particular regular blood glucose testing and regular exercise so that there is a need to improve diabetic self-care practice among diabetic patients. Attention should be given towards diabetic self-care practice by policy makers, Dessie referral hospital, health care professionals and diabetic associations. Researchers should also do further study by using qualitative approach to address the unreached problems in this study.

\section{Authors' contributions}

SGA: initiated the idea, develop the proposal, data entry, statistical analysis, interpretation of the data and writing the manuscript. SAK: edit the proposal, gave constructive comments to increase quality of the study and statistical analysis. SAA: develop the proposal, interpretation of the data and did pre-test. ADN: contributed to the pre-test of the tool, data entry and statistical analysis. KDT: edit the proposal and recruit data collectors. All authors read and approved the final manuscript.

\section{Funding}

The study financially supported by Wollo University. This University reviewed and approved the concept of the study to be conducted but had no role in the study design, data collection, analysis and interpretations of data.

\section{Acknowledgement}

The authors would like to acknowledge Wollo University for financial support to conduct this study. We thank all data collectors and supervisor participated in the study. Our deepest gratitude also goes to hospital administrators for providing information regarding the number of diabetic patients on follow up which helps us in organizing the sampling procedure used to undertake the study.

\section{References}

1. Kerner W, Brückel J. Definition, classification and diagnosis of diabetes mellitus. Exp Clin Endocrinol Diabetes. 2014; 122: 384-386. PubMed: https://pubmed.ncbi.nlm.nih.gov/25014088/

2. Lichtman SW, Pisarska K, Berman ER, Pestone M, Dowling $\mathrm{H}$, et al. Discrepancy between self-reported and actual caloric intake and exercise in obese subjects. New Eng J Med. 1992; 327: 1893-1898. PubMed: https://pubmed.ncbi.nlm.nih.gov/1454084/

3. American Diabetes Association. 2. Classification and diagnosis of diabetes: standards of medical care in diabetes-2019. Diabetes Care. 2019; 42: S13-S28.

PubMed: https://pubmed.ncbi.nlm.nih.gov/30559228/

4. Anderson RM, Funnell MM, Butler PM, Arnold MS, Fitzgerald JT, et al. Patient empowerment: results of a randomized controlled trial. Diabetes Care. 1995; 18: 943-949.

PubMed: https://pubmed.ncbi.nlm.nih.gov/7555554/

5. Welschen LM, Bloemendal E, Nijpels G, Dekker JM, Heine RJ, et al. Self-monitoring of blood glucose in patients with type 2 diabetes who are not using insulin: a systematic review. Diabetes Care. 2005; 28: 1510-1517.

PubMed: https://pubmed.ncbi.nlm.nih.gov/15920083/

6. Garcia-Perez LE, Álvarez M, Dilla T, Gil-Guillén V, Orozco-Beltrán D. Adherence to therapies in patients with type 2 diabetes. Diabetes Ther. 2013; 4: 175-194.

PubMed: https://pubmed.ncbi.nlm.nih.gov/23990497/

7. Coyle ME, Francis K, Chapman Y. Self-management activities in diabetes care: a systematic review. Australian Health Rev. 2013; 37 : 513-522.

PubMed: https://pubmed.ncbi.nlm.nih.gov/24018058/ 
8. Chen L, Chuang LM, Chang CH, Wang CS, Wang IC, Chung Y, et al. Evaluating self-management behaviors of diabetic patients in a telehealthcare program: longitudinal study over 18 months. J Med Internet Res. 2013; 15: e266.

PubMed: https://pubmed.ncbi.nIm.nih.gov/24323283/

9. Padma K, Bele SD, Bodhare TN, Valsangkar S. Evaluation of knowledge and self-care practices in diabetic patients and their role in disease management. National J Commun Med. 2012; 3: 3-6.

10. Shrivastava SR, Shrivastava PS, Ramasamy J. Role of self-care in managementofdiabetesmellitus.JDiabetesMetaboDisord.2013;12:14. PubMed: https://pubmed.ncbi.nlm.nih.gov/23497559/

11. Okolie VU, Ehiemere OI, Peace IN, Ngozi K-II. Knowledge of diabetes management and control by diabetic patients at Federal Medical Center Umuahia Abia State, Nigeria. Int J Med Medical Sci. 2009; 1: 353-358.

12. Shaw JE, Sicree RA, Zimmet PZ. Global estimates of the prevalence of diabetes for 2010 and 2030. Diabetes Res Clin Practice. 2010; 87: 4-14. PubMed: https://pubmed.ncbi.nlm.nih.gov/19896746/

13. Nathan DM. Long-term complications of diabetes mellitus. New Eng $\mathrm{J}$ Med. 1993; 328: 1676-1685.

PubMed: https://pubmed.ncbi.nlm.nih.gov/8487827/

14. World Health Organization. Global report on diabetes. 2016.

15. Breitscheidel L, Stamenitis S, Dippel FW, Schöffski O. Economic impact of compliance to treatment with antidiabetes medication in type 2 diabetes mellitus: a review paper. J Med Econ. 2010; 13: 8-15. PubMed: https://pubmed.ncbi.nlm.nih.gov/19947905/

16. Abdulameer SA, Sulaiman SAS, Hassali MAA, Subramaniam K, Sahib MN. Osteoporosis and type 2 diabetes mellitus: what do we know, and what we can do? Patient Prefer Adherence. 2012; 6: 435-448. PubMed: https://pubmed.ncbi.nlm.nih.gov/22791981/

17. Loganathan A, John K. Economic burden of diabetes in people living with the disease; a field study. J Diabetol. 2013; 4: 5.

18. ÇetinEN,ZencirM,FenkçiS,AkınF,YıldırımC.Assessmentofawareness of diabetic retinopathy and utilization of eye care services among Turkish diabetic patients. Primary Care Diabetes. 2013; 7: 297-302. PubMed: https://pubmed.ncbi.nlm.nih.gov/23639610/

19. Addisu Y, Eshete A, Hailu E. Assessment of diabetic patient perception on diabetic disease and self-care practice in Dilla University Referral Hospital, South Ethiopia. J Metabolic Synd. 2014; 3: 2167-0943.1000166.

20. Bonger Z, Shiferaw S, Tariku EZ. Adherence to diabetic self-care practices and its associated factors among patients with type 2 diabetes in Addis Ababa, Ethiopia. Patient Prefer Adherence. 2018; 12: $963-970$

PubMed: https://pubmed.ncbi.nlm.nih.gov/29922042/

21. Chali SW, Salih MH, Abate AT. Self-care practice and associated factors among Diabetes Mellitus patients on follow up in Benishangul Gumuz Regional State Public Hospitals, Western Ethiopia: a crosssectional study. BMC Res Notes. 2018; 11: 833.

PubMed: https://pubmed.ncbi.nIm.nih.gov/30477553/

22. Abate TW, Tareke M, Tirfie M. Self-care practices and associated factors among diabetes patients attending the outpatient department in Bahir Dar, Northwest Ethiopia. BMC Res Notes. 2018; 11: 800. PubMed: https://pubmed.ncbi.nlm.nih.gov/30409148/
23. Aschalew AY, Yitayal M, Minyihun A, Bisetegn TA. Self-care practice and associated factors among patients with diabetes mellitus on follow up at University of Gondar Referral Hospital, Gondar, Northwest Ethiopia. BMC Res Notes. 2019; 12: 591.

PubMed: https://pubmed.ncbi.nlm.nih.gov/31533833/

24. Berhe KK, Demissie A, Kahsay AB, Gebru HB. Diabetes self care practices and associated factors among type 2 diabetic patients in Tikur Anbessa specialized hospital, Addis Ababa, Ethiopia-a cross sectional study. Int J Pharmaceut Sci Res. 2012; 3: 4219.

25. Upadhyay DK, Palaian S, Shankar PR, Mishra P, Pokhara N. Knowledge, attitude and practice about diabetes among diabetes patients in Western Nepal. Rawal Med J. 2008; 33: 8-11.

26. Feleke SA, Alemayehu CM, Adane HT, Onigbinde A, Akindoyi O, et al. Assessment of the level and associated factors with knowledge and practice of diabetes mellitus among diabetic patients attending at FelegeHiwot hospital, Northwest Ethiopia. Clin Med Res. 2013; 2: 110.

27. Given CW, Given BA, Gallin RS, Condon JW. Development of scales to measure beliefs of diabetic patients. Res Nurs Health. 1983; 6 : 127-141. PubMed: https://pubmed.ncbi.nlm.nih.gov/6556699/

28. Adejoh SO. Diabetes knowledge, health belief, and diabetes management among the Igala, Nigeria. Sage Open. 2014; 4: 2158244014539966

29. Tegegne GT, Shiferaw A, Gelaw BK, Defersha AD, Linjesa MAW, et al. Glycemic control and self-care practice among ambulatory diabetic patients in ambo general hospital, West Showa, Ethiopia. Glob J Med Res. 2014; 14: 26-36.

30. American Diabetes Association. Standards of medical care in diabetes--2014. Diabetes care. 2014; 37: S14-80.

PubMed: https://pubmed.ncbi.nlm.nih.gov/24357209/

31. Ayele K, Tesfa B, Abebe L, Tilahun T, Girma E. Self care behavior among patients with diabetes in Harari, Eastern Ethiopia: the health belief model perspective. PloS One. 2012; 7: e35515. PubMed: https://pubmed.ncbi.nlm.nih.gov/22530039/

32. Mariye T, Tasew H, Teklay G, Gerensea H, Daba W. Magnitude of diabetes self-care practice and associated factors among type two adult diabetic patients following at public Hospitals in central zone, Tigray Region, Ethiopia, 2017. BMC Res Notes. 2018; 11: 380. PubMed: https://pubmed.ncbi.nlm.nih.gov/29895315/

33. Amente T, Belachew T, Hailu E, Berhanu N. Self care practice and its predictors among adults with diabetes mellitus on follow up at Nekemte hospital diabetic clinic, West Ethiopia. World J Med Med Sci. 2014; 2: 1-16.

34. Suguna A, Magal A, Stany A, Sulekha T, Prethesh K. Evaluation of self-care practices among diabetic patients in a rural area of Bangalore district, India. Int J Curr Res Aca Rev. 2015; 3: 415-22.

35. LiN, Yang X, Deng Y, Gu H, Ren X, etal. Diabetes self-management and its association with diabetic retinopathy in patients with type 2 diabetes. [Zhonghua yan ke za zhi] Chinese J Ophthalmol. 2013; 49: 500-506. PubMed: https://pubmed.ncbi.nlm.nih.gov/24119962/

36. Tan S, Juliana S, Sakinah H. Dietary compliance and its association with glycemic control among poorly controlled type 2 diabetic outpatients in Hospital Universiti Sains Malaysia. Malaysian J Nutrit. 2011; 17; 287-299.

PubMed: https://pubmed.ncbi.nlm.nih.gov/22655451/ 